degeneration, so that macroscopically hardly the outline of a tubule could be distinguished. In the present case the sudden onset in convalescence, the time of occurrence (twenty-first day), and the simultaneous appearance and long continuance of albumin in the urine together present a strong analogy to scarlatinal nephritis. The hæmatological findings are not inconsistent with this view. Moderate leucocytosis, the increase being mainly neutrophile, and a marked reduction in the number of eosinophiles, are changes equally characteristic of purpura and of the early stages of an intercurrent nephritis. I am disposed to believe that the coudition is due to the same toxic agent or agents-largely streptococcal in origin-as produce nephritis in other cases, that, in fact, it replaced an attack of the latter. Corroborative of this view is the disproportion between the extent of the hæmorrhages and the gravity of the general condition clearly pointing to an added toxæmia, while the rapid improvement is equally notable-a common feature in many cases of late scarlatinal nephritis. In this connexion, also, the character of the initial attack is important, as the majority of the recorded cases show prolonged pyrexia with severe faucial angina.

Two conditions touching prognosis suggest themselves. First, the age of the patient is markedly higher than in most of the other cases and is evidently a very weighty factor. Secondly, the rapid and great rise in the eosinophile values is very striking and would support the inference that in this, as in the other complications of scarlet fever, a steady increase of these elements is of favourable import. The significance of the slight basophilia present is obscure, although, using Wright's stain, I have occasionally noted fractional percentages in ordinary uncomplicated cases of scarlet fever. The increased coagulability of the blood and the rapid improvement in the general state under the administration of calcium chloride seem to point to a causal connexion, though recent researches indicate that the morbid lesion in hæmorrhagic diseases is to be sought for in the vessel walls rather than in the blood.

I am indebted to Dr. J. E. Beggs, medical superintendent of the Grove Hospital, for permission to publish this case.

Tooting, S.W.

\section{THE IMMEDIATE TREATMENT OF EXTENSIVE WOUNDS ON FIELD} SERVICE.

BY CLIFFORD ALLCHIN GILL, M.R.C.S. ENG., L.R.C.P. LOND., LLEUTENANT, I.M.S.

THE teaching of the Russo-Japanese war, so far as it has yet been published, bears out in the main our own experience in South Africa, which was, briefly, that early operative procedures on the severely wounded are dangerous beyond the degree which modern surgery would lead us to expect. On the Russian side, at any rate, primary laparotomies were rarely performed and amputations were only undertaken 322 times in 63,346 cases of wounded, or 0.5 per cent. We have yet to learn the work in the Japanese field hospitals; at the base hospitals at Hiroshima, Sasebo, and the naval hospital in the Elliot Islands the operations were all undertaken some considerable time after the injury was received and therefore, though highly successful, are foreign to the purpose of this paper.

At present, therefore, we are not substantially ahead of the teachings of the South African war, where the various distinguished surgeons who were sent out were not slow to point out the disappointing results of immediate operations (with certain exceptions, such as injuries of cranial bones); in this they were, perhaps, not uninfluenced by the marvellous recoveries made in a limited number of cases by the apparently mortally wounded, on whom no operation was performed. The result of their teaching is that the pendulum of opinion among military surgeons is swinging right round in this direction, and the tendeney at the present time is to undertake nothing but the most obvious temporary measures and to get the patient transferred as soon as possible to the nearest stationary field hospital or general hospital. It would follow from this that the operative skill would be concentrated in these hospitals to the exclusion of the field hospitals which remain in the immediate vicinity of the fighting line. This to my mind does not accord with a true reflection of the teachings of modern surgery. These, it is true, display nothing original, but are such as in their application to field service lay down very distinctly what should be the rôle of the regimental medical officer, the bearer company, and the staff of a field hospital-i.e., of those who are in a position to render first aid. At the same time these requirements are quite simple and are not inconsistent with the exigencies of military service.

The principles of treatment are, of course, (1) the arrest of hrmorrhage; (2) the prevention of shock; and (3) the prevention of sepsis. To carry out these elementary principles, and these alone, is the duty of those who render first aid. At the same time it is not inconceivable that a keen surgeon might wish on occasion to do more, both to save the patient's feelings in the future and with a view of saving valuable time subsequently; indeed, it was stated in THE LANCET that the Russian medical officers (regimental) were informed that they were only to attempt first aid and were rather disappointed to have to obey this order. But the rôle of the medical officer who renders first aid is by no means a minor one ; indeed, its importance cannot be over-estimated. He has to arrest hæmorrhage as best he may, to combat shock with warmth, stimulants (unless contra-indicated), and opium, the last being particularly valuable. For this latter purpose all medical officers and subordinates who carry hypodermic syringes should be provided with a solution of morphine for field service use instead of tabloids. An ounce bottle containing a freshly prepared solution in sterilised water of hydrochlorate of morphine of a certain strength-say one-third of a grain in five minims-would answer the purpose. This conld easily be prepared in field hospitals and distributed to corps as required. The advan. tages of this seem obvious. Lastly, and perhaps most important of all in extensive injuries, it is the duty of the medical officer who renders first aid to cleanse the wound and the surrounding parts with an antiseptic solution and after he has done this as thoroughly as circumstances permit to apply the first field dressing. These measures aim at cleansing a recently infected wound and preventing further contamination from outside and is a much easier proceeding than if undertaken at any later period, for the micro-organisms are at the most merely on the wound.

But it may be said, How can these objects be successfully attained on active service? The answer is, every soldier carries a first field dressing and a water-bottle. These can in an emergency be improvised into antiseptic solution and dressing respectively. To make the solution I would suggest that we adopt a plan used by the Japanese and let each soldier carry his own antiseptic tabloids. If in each field dressing from three to six tabloids of perchloride of mercury were included the antiseptic is supplied without difficulty and without adding to the weight the soldier has to carry or without being in any other way objectionable or inconvenient. All that would be required would be to dissolve one or more of them in the soldier's water-bottle (failing any other receptacle), remove débris, rinse the wound, and wipe it dry with a pledget taken from the gamgee tissue of the first field dressing, and finally dress it with the remainder of the latter. This would be a feasible procedure in a large majority of cases. The patient after once being dressed may be placed in a stretcher, doolie, or ambulance wagon and allowed to remain in some convenient spot whilst others are receiving attention. A delay of a few hours in sending him back to the field hospital will be convenient to the medical staff and highly beneficial to the patient who will be in the meantime, under the beneficial inflaence of opium, recovering from the shock. When he eventually arrives at a field hospital he will be in the best possible condition for undergoing an operation and may safely be anæsthetised to the full surgical extent if necessary. If on account of surgical considerations, lack of time, or military necessities the surgeon decides against operation, the patient stands the best chance of his wounds running an aseptic course, for the measures taken for the prevention of sepsis, if not very thorough, were at least undertaken at the best possible time-immediately after the injury. On removal of the first field dressing an aseptic wound would appear, in contradistinction to the freely suppurating wounds which I frequently saw on the operating table of a field hospital in South Africa when the first field dressing was removed. 
In conclusion, I would summarise these remarks on the immediate treatment of extensive injuries on field service by emphasising the following points: 1 . The immediate application of an antiseptic lotion to large wounds. 2. To pro vide the necessary antiseptic the addition of tabloids of perchloride of mercury to the first fie'd dressing packet is suggested. 3. Following the first dressing a period of rest may be allowed which is highly convenient to the medical staff and conducive to the well being of the patient. 4. Removal by ambulance transport to field hospital where operation may be undertaken on a patient whose vital powers have largely recovered from the shock consequent on his wounds. Jullundur, India.

\section{Clinital Alotes:}

\section{MEDICAL, SURGICAL, OBSTETRICAL, AND THERAPEUTICAL.}

\section{A NOTE ON THE TREATMENT OF CHOLERA BX SALINE INJECTIONS.}

By F. C. MCCombie, M.B. Lond.

I THINK it may be of interest to put on record the recent experienoes of my partner, Dr. J. D. Gregorson, and myself with the saline treatment of cholera in a recent epidemic on one of the big tea gardens under onr care. With the help of our able and energetic native helper, B. C. Dass, hospital assistant, we had a mortality of only 23.8 per cent. out of a total of 105 cases, although two subsequently died from dysentery and two from tetanus some time after complete recovery from cholera; another dying from tetanus on the fourth day has been included in our cholera mortality. Of the 25 deaths from cholera, seven patients died immediately after admission before saline solution could be given. Only the worst of the other cases were treated by injection, 73 in all, among whom the mortality was 26 per cent., which we think may be regarded as a ver: satisfactory result.

Our general method of treatment is as follows: On admission the patient gets hypodermically from one-sixth to onefourth of a grain of morphine, followed by 20 minims of spirit of ether every four hours and perhaps digitalin according to the pulse. Also by the mouth we give ten grains of calomel and ten grains of bicarbonate of sodium in one dose, and then the following mixture every three hours: Carbolic acid, two minims; bicarbonate of sodium, ten grains ; carbonate of bismuth, ten grains; aromatic spirit of ammonia, 15 minims; spirit of chloroform, ten minims ; and peppermint water to make up one ounce. Hot-water bottles and friction to the extremities are also applied and the patient is allowed to drink freely of water slightly acidulated with twenty minims of sulphuric acid to a pint. Then if signs of reaction do not appear salt solution (60 grains to one pint of boiled water) at a temperature of from $105^{\circ}$ to $110^{\circ} \mathrm{F}$. is injected into the subcutaneous tissues over the axillæ, the breasts, and the epigastrium. As soon as the fluid ceases to flow readily into one place the needle is with drawn and inserted int ) another, the swelling resulting from the injection being firmly rubbed to promote absorption. By this method we had no difficulty in getting large quantities absorbed; some of our cases had as much as nine pints and none lass than two pints. The injection is continued unti the pulse shows signs of improvement and at any sign of failure it is recommenced

This method of procuring rapid and continuous absorption seems to be the important point in the treatment, and to the fact that a sufficient quantity of fluid has not always been introduced must be attributed the unsatisfactory results which have formerly been obtained by this treatment. Hence this communication is made simply to draw attention to a very valuable method which seems, owing to its non-efficient uss, to be becoming neglected.

The apparatus in its simplest form consists of a douchecan suspended at a height of from one to two feet above the patient, joined by a length of rubber tubing (with a clip) to a medium-sized aspirating needle. With ordinary antiseptic precautions we had only a few cases of abscess following injection and unfortunately three of tetanus, but each of these had septic wounds elsewhere at the time which would have provided a suitable nidus for the bacillus tetani. One patient died on the fourth day after receiving his injection; he had sores due to scabies. One woman had ulcers on her leg and died three weeks after her cholera treatment, whilst the third, with an ulcer of the vulva, succumbed to lockjaw after 17 days. Furthermore, all these three cases took place in one of the primitive houses of grass and bamboo, of which our temporary isolation hospital was composed, in the middle of a stretch of grass land ordinarily used as a grazing ground. This house was burnt down and no more tetanus occurred.

Two of the cases were tried intravenously with the addition of ten minims of adrenalin chloride $(1$ in 1000) to the pint of salt sulution. The immediate effect was marvellous, one patient rousing from a pulseless dying stage to absolute cheerful consciousness in half an hour. This man came in with dysentery and recovered. Three days later he was attacked with cholera, was treated with adrenalin as above, and improved, but got a relapse on the third day, which was treated by salt solution subcutaneously and left him very weak and exhausted and he gradually fell into a dul comatose condition and died on the eighth day after his first attack of cholera. Tne other case tried with adrenalin died also in a relapse. A third case treated with simple salt solution intravenously did not recover. Adrenalin was also tried in 10-minim doses by the mouth and the results were so good that we think it is worth further trial.

On another garden where cholera and choleraic diarrhoe are always endemic during the hot weather we had eight deaths out of 18 cases last year. This year, since the introduction of the saline treatment, we had 30 cases with only one death, while on a neighbouring tea garden where the saline treatment was not used nearly all the cases died, which we think is further proof of our point that the saline treatment of cholera when properly carried out is of the greatest value in this very fatal disease, the average mortality of which works out at about 50 per cent.

Tinsukia, Upper Assam, India.

\section{A CASE OF MENINGEAL H FMORRHAGE} RESEMBLING HYSTERIA.

By Herbert J. WALKER, M.R.O.S. ENG., L.R.C.P. LOND.

I WAS recently sent for in the evening to see a man who was said to be in a fit. The history told me by the messenger was to the effect that the man whilst in a publichouse talking to some friends suddenly fell backwards into their arms and that they immediately laid him on the floor when he commenced to struggle violently. His home being close by they carried him to it and placed him on the bed but had great difficulty in doing so, as he struggled so much. When I saw the man he was lying on the bed being held down by two men. Thinking that the case was in all probability one of hysteria I told the men to leave the man alone. I then pressed on the patient's supraorbital nerves in order to try to bring him round, but he only struggled violently, never speaking a word and tried to get his head away. Still thinking it a case of hysteria, since there were no true convulsions as in epilepsy of cerebral hæmorrhage, I applied cold water to his head and the back of his neck without any good effect at all. Fearing that he might tumble off the bed, as it was difficult to hold him on, we placed him on the floor when he threw himself into all sorts of positions, rubbing his head along the floor, attempting to get up, then falling back again, but there were no true opisthotonic or orthotonic movements. His breathing all this time was quick and he foamed slightly at the mouth, this being due to the man blowing his breath out, very much in the same way as a hysterical patient does when he tries to simulate epilepsy. No blood came from the mouth, nor did any of his facial muscles appear to be paralysed or contracted. His pulse was full and fairly quick but nothing very abnormal. I next ordered him to be put back in bed and gave him a hypodermic injection of half a grain of morphine and had him strapped down to the bed, as he still struggled very much. A bout 20 minutes after giving him the morphine the struggles ceased, so I attempted to look at his pupils, but directly I touched him the struggles started again and all I could see was that the eyes were turned upwards, but after persevering I managed to see the pupils which were neither dilated nor contracted, but I could not test for the reaction 